\title{
Excretion of Steroid Hormones in Rodents: An Overview on Species Differences for New Biomedical Animal Research Models
}

\author{
Juan Manuel Busso ${ }^{1,3}$ and Rubén Daniel Ruiz ${ }^{2,3}$ \\ ${ }_{1}^{1}$ Instituto de Ciencia y Tecnología de Alimentos, Facultad de Ciencias Exactas, Físicas y \\ Naturales (FCEFyN) - Universidad Nacional de Córdoba (UNC)/ Consejo Nacional \\ de Investigaciones Científicas y Técnicas (CONICET) \\ ${ }^{2}$ Instituto de Fisiología, Facultad de Ciencias Médicas, UNC \\ ${ }^{3}$ Established investigators from the CONICET \\ Argentina
}

\section{Introduction}

Living organisms have regular patterns and routines that involve obtaining food and carrying out life-history stages such as breeding, migrating, molting and hibernating. The acquisition, utilization, and storage of energy reserves (and other resources) are critical to lifetime reproductive success, and this reproductive process could be affected by predictable and unpredictable environmental changes (McEwen and Wingfield, 2003; Schneider, 2004). Allostasis is achieving physiological stability through change (see details in McEwen and Wingfield, 2003); the allostatic state refers to altered and sustained activity levels of the primary mediators, i.e., glucocorticosteroids that integrate physiology and associated behaviors in response to changing environments and challenges. Focused on these primary mediators, particularly in steroid hormones, it has been well accepted for a long time that variations (increases) of adrenal glucocorticoids are associated with stress responses. Moreover, measuring changes in glucocorticoid concentration (and also in levels of adrenaline and noradrenaline) has been the most frequently used strategy to monitor physiological responses to stress and distress challenges (Terlouw et al, 1997; Wielebnowski, 2003; Mormède et al, 2007; Sheriff et al., 2011). In terms of changes in steroid secretory patterns in response to a stressor, glucocorticoids are known to change over the course of minutes and those levels will subsequently (within hours to days) affect steroid reproductive hormones (such as testosterone, estradiol and progesterone) (Sapolsky et al., 2000).

While experiencing severe stress, animals, as humans, can succumb to disease or fail to reproduce or develop properly (Moberg, 2000). Therefore, animals have evolved a suite of physiological and behavioral strategies to cope with environmental changes as well as to survive in a particular given time and space (Buchanan, 2000; Romero, 2004). Therefore, "environmental endocrinology" has developed in response to the need to understand how hormones modulate and control physiological processes in animals exposed to the exigencies of their particular natural environment. This has only been possible through 
spectacular developments in hormone assay techniques, which now make feasible hormone measurements on microlitre volumes of body fluids (Bradshaw, 2007). Four biological samples have been employed up to the present: blood, saliva, excreta (feces and urine), and integumentary structures (hair and feathers), each of them having advantages and disadvantages for use with different species and research purposes (Sheriff et al., 2011).

Blood collection continues being an attractive and reliable technique for steroid analysis; several reports for different species are available in the literature, such as for Japanese quail (Arora, 1979) or chinchilla (Tappa et al, 1989); these species-specific reports provide recommendations on safety, ease of collection and repeated collections. However, in a study of endocrine dynamics this approach may be impractical because blood extraction is a powerful stressor and it is known that within minutes, glucocorticoid secretion is stimulated and gonadal steroid secretion declines. For example, blood samples collected only from birds reflect unstressed (baseline) glucocorticoid concentrations with a high degree of confidence within less than 2 minutes (Sapolsky et al., 2000; Romero and Reed, 2005). In addition, when experiments involve small animals it is usually difficult to obtain the necessary blood volume, and repeated blood sampling can interfere with subsequent hormone measurements, and it may even be harmful as it has been reported for chinchilla. In large-sized bird and mammalian species, such as Greater Rhea (Léche et al., 2009) and Clouded Leopard (Wielebnowsky et al., 2002), blood collection may be dangerous for the operator and certainly stressful for animals. Blood sample collection is always a critical procedure in the laboratory, and an impractical approach in nature without the aid of auxiliary techniques (such as anesthesia); therefore, these "Gold" microliters of plasma/serum are always appreciated by researchers. Hormones secreted by adrenal and gonad glands go through the bloodstream to their target tissues and cells, where they initiate a change in cellular activity by attaching to a receptor protein. Thereafter, steroids are excreted into the bile to undergo metabolic changes in the intestinal tract due to the enzymatic activity of the intestinal microflora. Also, enterohepatic recirculation of steroid metabolites, with possible further metabolic changes in the liver, is known to occur in many species. The reabsorbed metabolites may be excreted in the bile again or pass into urine (Taylor, 1971). Evaluating steroid metabolite content and/or profiles in either urine or feces represents an alternative technical approach without perturbing individuals, populations or animal species. This experimental strategy has been applied to a wide range of research goals in captive and free-ranging wildlife, as well as domestic and laboratory species. Several reviews focusing on steroid metabolism and the validation of particularly fecal steroid assays have been published in the last years (Schwarzenberger et al., 1996; Brown and Wildt, 1997; Monfort, 2003; Palme et al., 2005; Schwarzenberger, 2007).

The obvious advantage of assessing urinary or fecal hormone concentrations is that adrenal and gonadal functions can be determined without even touching the animal: the waste is simply recovered from the adequately arranged ground or enclosure floor and analyzed in the laboratory. Resulting hormonal profiles are generally less "noisy" than those observed after analyzing blood because the excretory patterns represent a pool of metabolites rather than reflecting the often hour-to-hour fluctuating dynamism quantified in blood (Pukazhenthi and Wild, 2004). According to recent reviews, it seems that this approach, noninvasive monitoring, will be utilized more than ever when well-focused endocrine issues are addressed and some steroids are involved (Palme and Möstl, 2002; Pukazhenthi and Wildt, 2004; Palme, 2005; Schwarzenberger, 2007). In fact, international programs have trained science students, especially researches from Latin American PhD programs (Swanson and Brown, 2004), as it 
can found in the reports of Busso et al. (2005a, 2007), Ponzio et al. (2004) in Argentina, of Brousset Hernández-Jauregui et al. (2005) in Mexico, and of Moreira et al. (2007) in Brazil. Similarly, new studies fully developed in traditionally called developing countries are clear evidence of the usefulness of this non-invasive approach (Leche et al., 2009, 2011). Furthermore, national funds or grants in these developing countries are becoming available to develop this type of noninvasive hormone research; e.g., in Argentina, new doctoral fellowships are being granted to support these studies.

A particular disadvantage of fecal steroid analysis is the presence of a vast number of different fecal steroid metabolites even in closely related species. For the development of techniques for fecal steroid analysis, experiments on the metabolism of radioactively labeled steroids have provided a valuable insight into the metabolism and excretion of hormone metabolites via feces and urine (Schwarzenberger, 2007; see discussion below). By contrast, steroids voided into urine are not extremely degraded; however, the use of urine steroids has the particular disadvantage that urine collection in some animals requires restraint in a metabolic cage, surgical interference or rigorous surveillance to collect samples during urination (Peter et al., 1996; Monfort, 2003). In non-invasive monitoring of steroid activity, several aspects must be considered before undertaking a new study, and/or focusing on a new species, or applying a new immunoassay (Millspaugh and Washburn, 2004; Buchanan and Goldsmith, 2004; Palme, 2005; Touma and Palme, 2005; Wielebnowski and Watters, 2007; Hayward et al., 2010).

When we intend to measure steroid metabolites in excreta, firstly we need to obtain them, usually by an extraction technique that should be simple, safe and efficient. Secondly, we usually need an immunoassay to detect (accurately, precisely, and specifically) variation of steroid levels in the matrix of interest. All these laboratory and validation steps as well as interpretation of results are strongly affected by information about steroid metabolism and catabolism; animal biological characteristics must be also taken into account (individual development, reproductive stage, nutritional strategy, copying strategy, etc.) during result analysis. Although we have not focused our revision on these aspects, the reader must be aware of them and their importance in the application of non-invasive monitoring.

As we have addressed steroid excretion, we need to know some aspects about steroid excretion before employing some immunoassays to reveal steroid activity: 1) route of excretion of each hormone to be evaluated, 2) time-course of steroid secretion in bloodstream and its clearance into urine and feces, 3) proportion of excreted metabolites during biological cycles, 4) identification of steroid metabolites in the matrix selected. These variables may be determined by injecting the hormone, usually a radiolabeled steroid or, less frequently, a large amount of unlabeled steroid and tracking their metabolite excretion over time. For example, Wielebnowski and Watters (2007) indicate that the types of fecal steroid metabolites excreted, the main route of excretion, and the time it takes for metabolization and excretion to occur should be identified before selecting an antibody and assay system. Normative data on steroid excretion is essential for improving the application of non-invasive monitoring; in addition, this information would be an extraordinary source of knowledge to compare several aspects of animal environmental endocrinology.

Therefore, based on updated endocrine data from wild, laboratory and farmed rodents, we propose to develop a comparative endocrine survey of the routes of gonadal and adrenocortical steroid excretion. In our laboratory, chinchilla were subjected to radiometabolism studies of progesterone, corticosterone, testosterone and estradiol (Ponzio 
et al, 2004; Busso et al, 2005a, 2007). Since domesticated chinchilla still share some genomic characteristics with their counterparts in the wild, the analysis would serve as an adequate example of widely diverse interests (scientific, ecological, economic, cultural and emblematic values). Basically, our endocrinological studies contribute with some specific data from this particular large rodent to the existing data for other rodents. The information provided can be helpful for:

In situ studies: 1- assessment of ecological phenomena, focused on environmental endocrinology, i.e. by quantifying field concentrations of stress hormones in individual organisms; 2- identification of healthy individuals from endangered wild populations to develop reproductive ex situ programs.

Ex situ studies: 1- diagnosis of reproductive functions and dysfunctions of valuable farmed individuals 2- application of assisted reproductive techniques; 3-improvement of welfare of animal model for studying biomedical research; 4- development of new experimental biotypes for the study of hormonal disruptive effects of environmental pollute.

In general, reviews about those topics have apparently neglected information about rodents. These animals are not regarded as threatened mammals, and public appreciation about their biological importance is scarce and tends to overlook the ecological role and conservation problems of an order representing about $41 \%$ of mammalian species (Gippoliti and Amori, 1998; Amori and Gippoliti, 2001, 2003). However, the order Rodentia is a tremendous biodiversity example of life strategies, with more than 2000 species, which encompass a staggering diversity of form, behavior and physiology. Additionally, scientists have frequently employed several rodent species to conduct research, and have used rodents even as animal models for biomedical studies.

\section{Excretion of steroid hormones}

Nowadays, it is widely accepted that basic knowledge of the metabolism and excretion of glucocorticoids is necessary for the development of a non-invasive technique to monitor adrenocortical activity (Möstl and Palme, 2002). Similarly, information of sex steroid metabolism is essential to monitor steroidogenic activity of gonads (Brown et al, 1994). The first step in assay development is identifying the excretory routes for each hormone of interest; conducting an infusion study would be extremely valuable in domestic and nondomestic animals, if captive-held counterparts are available and the tests are feasible (Wielebnowski and Watters, 2007), such as the studies performed in domestic chinchilla to evaluate wild chinchilla (Busso et al, 2005a, 2007; see further details below). We also accept that, in practical terms, it is unnecessary to determine the specific molecular structure of the hormones being monitored in each species. However, it is critical to demonstrate that fluctuations in the hormone metabolites being measured provide physiologically relevant information (Monfort, 2003). Accordingly, it is well accepted that endocrine glands must be challenged to monitor their activation, e.g., by injecting ACTH or dexamethasone and measuring whether glucocorticoid levels in the tested matrix reflects the predicted changes in the blood. The use of a biological test or the so called "biologically relevant tests" (that expose an animal to a biological stressor to measure the glucocorticoids in samples) is also recommended; this ensures that the noninvasive monitoring will appropriately measure glucocorticoids in the field when animals are exposed to genuine stressors (Sheriff et al., 2011). Several reports may be useful to set up an experimental design for applying a noninvasive approach (Brown and Wildt, 1997; Wasser et al., 2000; Palme and Möstl, 2002; 
Buchanan and Goldsmith, 2004; Millspaugh and Washburn, 2004; Palme, 2005; Goymann, 2005; Klasing, 2005; Palme et al., 2005; Wielebnowski and Watters, 2007).

Pharmacological and biological relevance tests are truly useful for validating non-invasive endocrine monitoring. Nevertheless, such validations should not miss the radiolabelling studies, since these allow us to discover, investigate and/or discuss the functional relevance of steroids. In fact, steroid receptors and the co-evolution of steroidogenic enzymes and steroid-inactivating enzymes had an important role in the evolution of complex regulatory networks in vertebrates, contributing to vertebrate survival and diversification in the last 500 million years (Baker, 1996, 2003).

Cholesterol is the precursor of the five major classes of steroid hormones. According to their number of carbon-atoms, these classes are: progestagens, glucocorticoids (and mineralcorticoids, C21); androgens (C19); and estrogens (C18). Because of their common precursor cholesterol, they are apparently all structurally related across birds and mammalian species; however, they show strong functional differences. Steroid hormones bind to intracellular proteins, termed receptors, which function as transcription factors. The receptors are specific for a given class of steroid. These receptors are members of the large superfamily of nuclear hormone receptors that include different hormones such as glucocorticoids, mineralocorticoids, vitamin A, thyroid and retinoids, as well as sex steroids (Brown, 1999). It is also well known that steroid hormones are synthesized in a number of endocrine tissues, mainly gonads, adrenals, and placenta.

Steroid hormones are dissociated from their receptors and metabolized by the target cell or the liver, which possess enzymes capable of altering the specific steroids and rendering them biologically inactive and water soluble. Typically, inactivation involves reduction or removal of side chain or attached groups or both, as well as the combination with other molecules (conjugation), such as glucose, to form a glucuronide or conjugation with sulfate. The relative emphasis on sulfate or glucuronide varies depending on the steroid and/or species (Norris, 2007). During this inactivation process, steroids are metabolized in the liver and excreted via the bile into the gut. Enterohepatic recirculation of steroid metabolites, with possible further metabolic changes in the liver, may facilitate steroid metabolite reabsorption; the reabsorbed metabolites would be excreted in the bile again or pass into urine. More than 40 years ago, Taylor (1971) revised studies on the excretion of steroid hormone metabolites in bile and feces. Regarding steroid metabolites, those of the less polar molecules tend to be excreted in bile to a greater extent than metabolites of polar steroids; e.g., progesterone metabolites are mainly present in bile (and feces). In contrast, hydrocorticortisone (cortisol) is almost completely excreted as urinary metabolites. On the basis of evidence reviewed, a hypothesis was postulated suggesting that the membrane of the bile canaliculi would have receptor sites specific for certain steroids metabolites (Taylor, 1971). The binding of these substances at the receptor sites is an obligatory step prior to active transfer of the substances across the canalicular membrane. In "primitive" mammals, such as rats and mice, the receptor sites have poor specificity and are therefore able to bind metabolites of most steroid hormones. In other species, evolution has resulted in a decrease in the number, specificity and binding capacity of these sites. Therefore, some steroid metabolites are partially bound and so excreted into bile (e.g., progesterone), whereas others are less firmly, or not, bound and therefore return to the blood by a passive or active transport. This hypothesis seems to go some way to explaining the difference in biliary excretion of steroid metabolites among species, and the excretion of different steroids by the same species. Radioinfusions have offered data as new evidence for increased caution in the inferences due to differences between species. 
As pointed out above, it is possible to evaluate gut passage time using radiometabolism studies, in which radio-labeled steroids are usually injected and then clearance of radioactivity into urine and faecal compartments is monitored (Brown et al., 1994; Palme et al., 1996); this procedure reflects time delay quite precisely and therefore provides a rough estimate of the expected delay. The delay time between circulation of steroids in plasma and their appearance in urine samples is usually rather short (less than $5 \mathrm{~h}$ ), but fecal steroid metabolites have an appreciable lag time (Palme et al., 1996; Schwarzenberger et al., 1996). For example, lag time or time course of fecal excretion may range from less than 30 minutes to more than one day, depending on the species, sometimes even within species, depending on the activity rhythms of animals (Palme and Möstl, 2002; Monfort, 2003; Palme, 2005). Recently, Touma et al. (2003) indicated that metabolism and excretion of corticosterone in urine and feces of mice are not only significantly affected by sex, but also by the time of day when the radioactive peak was observed (after administration). Several radiometabolism studies demonstrated that oestrogens in the form of estradiol and/or estrone are present in fecal samples; by contrast, testosterone, progesterone and, especially, cortisol/corticosterone are heavily metabolized and the original hormone is barely present in the feces (Schwarzenberger, 2007). Therefore, the route of excretion varies considerably among species, and among steroids within the same species.

This chapter focuses on the updated comparative endocrine analysis of the routes of excretion of gonadal and adrenocortical steroids, taking into account the published information on non-invasive analyses being used by a variety of scientists (e.g., conservation biologists, animal scientists) to examine glucocorticoid (i.e., stress hormone) and gonadal steroids (i.e. reproductive hormones) secretion in domestic and wild rodents. Also, radiolabeled procedures have also provided useful results for testing the efficiency of different protocols for extracting hormones from samples (Schwarzenberger et al, 1996).

\section{Measurements of steroids in rodent excreta: Use of radiolobelled infusions for evaluation of corticosterone/cortisol, progesterone, testosterone and estradiol catabolism}

Over $40 \%$ of mammal species belong to the order Rodentia. While rodents are often thought of as just mice and rats, more than 2000 species in this order encompass a staggering diversity of form, behavior and physiology. In fact, excluding the human species, the order Rodentia is the group of most prosperous modern mammals, occupying very different ecological niches in almost all the planet, mostly specialized in rapid reproduction that can be adjusted to different circumstances (Conaway, 1971; Young, 1985; Bronson, 1999). At present, based on rodent morphology of their lower jaw, living rodents are divided into two suborders: the Sciurognathi (squirrel and mouse-like forms) and the Hystriocognathi (cavylike forms). Although this classification might still be a matter of debate as well as those based on the long-standing division of the insertion patterns of masseter muscles or the plane of incisor insertions (Mess et al., 2001; Huchon et al., 2002; Kay et al. 2008), these aspects are beyond the scope of present review. We currently support or choose the present classification of rodents as squirrel and mouse or cavy-like forms. It has been proposed that Rodentia is a monophyletic group; however, several molecular studies have suggested that the guinea pig and its relatives (such as Hystriocognathi or cavy-like forms) are closer to other orders of mammals than to families of rats and mice. For example, taking into account that insulin is a conservative molecule in mammals, as we might think of steroids, 
Hystricognathi species represent an exception having a very divergent molecule with unusual physiological properties among rodents (Opazo et al, 2005).

In our laboratory, we have been studying aspects of reproductive biology in chinchilla (Chinchilla lanigera) for over 15 years (Ponce et al., 1998a, b; Carrascosa et al., 2002; Ponzio et al., 2004, 2007a, b, 2008; Busso et al., 2005a, b, c, 2007). This is an interesting taxon, since domesticated chinchilla used for the fur industry still share some genomic characteristics with their endangered (almost extinct) counterparts. Actually, Chinchilla spp. are critically endangered in South American wild populations according to the IUCN (IUCN/SSC Rodent Specialist Group):

\section{Wild rodents \\ Chinchilla lanigera, a chinchillid from the Cordillera de la Costa and rocky Andean slopes of Chile (400-2500 m asl), which is threatened by the fur trade and habitat loss due to overgrazing, firewood collection, and mining.}

Chinchilla brevicaudata, another chincillid from the central Andean region of Peru, Bolivia, Argentina, and Chile. This species inhabits at higher altitudes (over 3,000 m asl), and is also threatened by the fur trade. Although its actual status is poorly known, it is already extinct in Argentina and Peru and probably is facing extinction in other parts of its range.

The Convention on International Trade in Endangered Species of Wild Fauna and Flora (CITES), lists in Appendix I all South American populations of Chinchilla, but no other rodents. According to Lidicker (IUCN/SSC Rodent Specialist Group, 1989), these listings by IUCN and CITES do not mean for sure that the populations of most rodent species are in good health, but only that we know very little about them.

Box 1. a status in nature must be verified in CITES and IUCN before start a new radiolabelled steroid infusion

Back to steroid hormones, most of the knowledge about endocrine modulation of reproductive physiology in Chinchilla spp. has been derived from studies in females (Tam, 1971, 1972; Brookhyser and Aulerich, 1980; Gromadzka-Ostrowska and SylarskaGozdz, 1984; Gromadzka-Ostrowska et al., 1985). With respect to the male endocrine reproductive physiology, Cepeda et al. (2006) obtained a plasma testosterone profile during the annual reproductive cycle, showing that endocrine activity increased immediately before the breeding season. Other studies performed using blood sampling have also been reported in chinchilla (Brookhyser et al., 1977; Tappa et al., 1989); however, serial samples taken over time induced injury in some animals. Alternatively, we validated a tool for non-invasively assessing endocrine testicular and ovary activity as well as adrenocortical activity by detecting hormone changes in excreta (Ponzio et al., 2004; Busso et al., 2005a, 2007).

We subjected some males and females to radiometabolism studies of testosterone, and progesterone and estradiol, respectively; we also studied corticosterone excretion in males. Firstly, after assessing ${ }^{14} \mathrm{C}$-testosterone metabolite excretion in male chinchilla (Busso et al., 2005a), several urinary and fecal androgen metabolites were separated by HPLC for their identification, but only fecal metabolites were associated with native testosterone. More than one metabolite derived from ${ }^{14} \mathrm{C}$-testosterone showed immunoreactivity and further 
biochemical and biological tests demonstrated that the employment of excreta would be useful to assess endocrine testicular function in this species. In female chinchillas, we also performed radiolabeled infusion of ${ }^{3} \mathrm{H}$-estradiol and ${ }^{14} \mathrm{C}$-progesterone, but in contrast to testosterone assessment, natural steroids were evaluated (were separated by HPLC-UV) in urinary and fecal extracts from pregnant individuals. This is a particular protocol to avoid the use of radioactive material in technical procedures, as normally expected at present. Chromatographic analyses demonstrated that most peaks were associated with the polar mobile phase in urine, whereas in feces, there were both polar and non-polar peaks. All HPLC fractions were individually analyzed by UV detector and by estradiol or progesterone immunoassays. These experiments suggest that chinchillas excrete native forms of progesterone and estradiol in low concentrations in urine and feces, whereas only progesterone-derived metabolites appear to be present in both excreta (Busso et al., 2007). Figure 1 depicts reproductive endocrine normative data with respect to route of steroid excretion in chinchilla (Hystricognathi rodent).

\section{Radioinfusion studies in chinchilla}

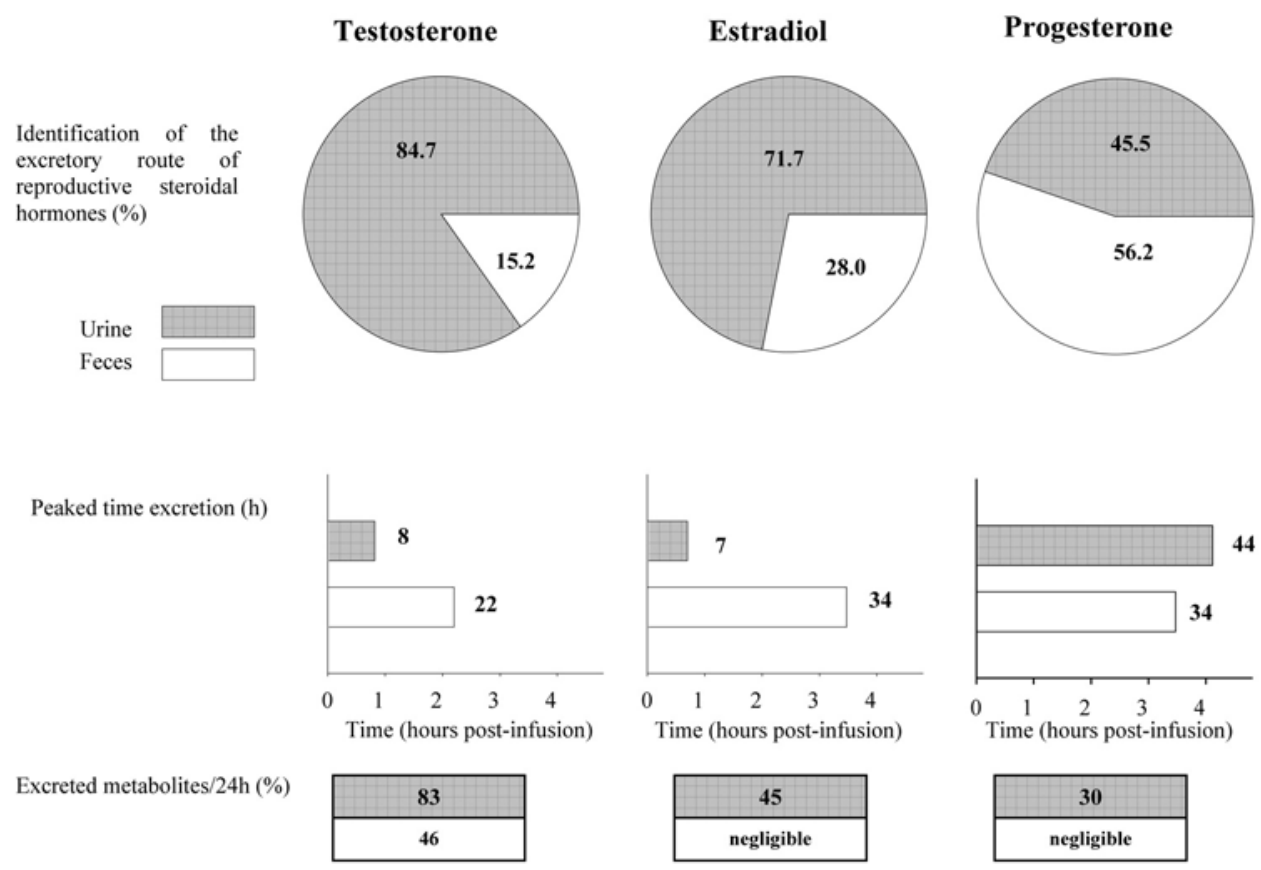

Fig. 1. Characterization of testosterone metabolite excretion in urine and feces after isotope administration (i.m.) in chinchilla males ( $n=4$; details in Busso et al. 2005a). Similarly, estradiol and progesterone metabolite excretion in excreta after isotope administration (i.p.) in chinchilla females ( $\mathrm{n}=4$; details in Busso et al. 2007).

Furthermore, in the same experimental model, we also established that the urinary route of corticosterone excretion was predominant in male (Ponzio et al., 2004) and HPLC analysis revealed that most corticosteroids are excreted as readily hydrolysable steroid conjugates of 
cortisol. Results shown together with data on corticosterone excretion in Figure 1 clearly demonstrate that urine is the main route, except for progesterone, where radioactive metabolites were almost equally found in urinary $(45.5 \pm 13.5 \%)$ and fecal extracts $(56.2 \pm$ $4.9 \%)$. As expected, radioactive peaks generally appeared earlier in urine than in feces. However, estradiol and progesterone radioactive metabolite time-courses showed great individual differences between $24-48 \mathrm{~h}$ post infusions, the highest percentages of excreted radioactive metabolites being detected during $48 \mathrm{~h}$ post-infusion.

Interestingly, based on these results from our radiometabolism studies and those reported for other rodents subjected to radiolabeled infusion up to this moment, we considered that the route of steroid metabolite excretion varies depending on the rodentia suborder. Therefore, it was proposed that the urinary route is preferential in Hystrichomorpha (chinchilla and guinea pigs; currently considered cavy-like forms) while in the Sciurognathi (squirrel and mouse-like forms, formerly considered Sciumorpha or Myormorpha suborders), the primary excretory route is the feces (Busso et al., 2006, Ponzio et al., 2006).

To our best knowledge, Taylor (1971) provided the best compilation of radiometabolism studies in mammalian species reported in the literature up to the present. Two of Taylor's major conclusions are relevant for our purposes: a) different steroids are excreted to different extents in urine and feces; this is evident, for example, in our comparative endocrinological studies in chinchilla (see Figure 1); and b) the same steroid is excreted to different extents in urine and feces of different species; reports revised by Taylor in the 1970s and most of the reports published thereafter are included in Figure 2. In this illustration our compilation is arranged according to our hypothesis of preferential route of steroid metabolite excretion in Rodentia suborders (see details in legend). It can be useful to take into account certain physical-chemical natural characteristics of steroids; considering the physico-chemical characteristics of steroid polarity, steroids are firstly shown in Figure 2 according to their water solubility (considering that steroids are heavily metabolized and the original hormone is barely present, particularly in the feces). Anyway, according to recent revisions, taxonomic relatedness does still little to predict the precise nature of metabolites or their relative routes of excretion (urine versus feces; Palme et al. 2005; Schwanzenberger, 2007).

\subsection{Hystricognathi (cavy-like forms)}

Both Guinea pigs and chinchilla are commonly employed as animal models in biomedical investigations. These species belong to the hystricomorph group of rodents that are well represented in South America, and have remarkably long reproductive cycles compared to other rodents.

Few studies on the comparative aspects of steroid metabolism and excretion in cavy-like forms (chinchilla and guinea pig) are available; published data of most reproductive steroids indicate that they are excreted mainly by urine (except for progesterone in chinchilla, see above). Fewer studies are available for sex steroids in this group of rodents; Bogdan and Monfort (2001) evaluated fecal estrogen and progesterone profiles in breeding and non-breeding females of the North American porcupine (Erethizon dorsatum; Erethizontoidae family). For glucocorticoids, cortisol is the main adrenal steroid hormone present in guinea pig plasma (Malinowska and Nathanielsz, 1974). No studies applying radiolabeled glucocorticoids in guinea pig have been conducted according to our last search, but apparently cortisol metabolites are found in large quantities in urine (Fajer and Vogt, 1963). 
Results of the application of a non-invasive technique in chinchilla indicate that glucocorticoids would present mainly in urine (Ponzio et al., 2004), and that cortisol would also be the main adrenal steroid. Cortisol was also detected in an experiment employing a cortisol RIA in blood samples of Octodon degus (Octodontoidae family); in addition, an ACTH positive effect on blood cortisol profile and cortisol fecal metabolite excretion was detected (Soto Gamboa et al., 2009). However, in the latter study it is difficult for us to establish a close correlation between results from different matrices because of sampling regimens.

\subsection{Sciurognathi (squirrel and mouse-like forms)}

Rats and mice are also widely used as animal models of human diseases in biomedical research. Other rodents such as those in the sciurid group, e.g., ground squirrel, have been extensively used as mammalian models of ecology, population regulation, and behavior. Nevertheless, Lepschy et al. (2007), as other authors, argued that the small body size of rodents and difficulties involved in blood sampling make it difficult to apply an invasive procedure. We should keep in mind that stress is a significant source of experimental errors and a major cause of stress in laboratory animals, and reducing stressful conditions in normal husbandry and in application of methods is essential to achieve an adequate level of reliability in the experimental results (Dahlin et al., 2009). Therefore, a non-invasive technique to monitor stress hormones in these animals is highly desirable (Siswanto et al., 2008; Touma et al., 2004; Thanos et al, 2009; Kalliokoski et al., 2010).

Likewise, Harper and Austad (2000) developed a noninvasive method for measuring adrenal activity in house mice, deer mice, and red-back voles (members of Muridae and Cricetidae families), as other authors did in old field mice (Cricetidae family; Good et al., 2003), in spiny mice (Acomys cahirinus; Muridade family) (Nováková et al., 2008; Frynta et al., 2009), in agouti and non-agouti deer mice (Peromyscus maniculatus; Cricetidae family) (Hayssen et al., 2002), and in Columbian ground squirrel (Sciuridae family) (Bosson et al, 2009). Similarly, although most of those authors did not perform a previous radioinfusion study, a noninvasive assessment proved to be useful also in different reproductive studies conducted in others small rodents (DeCantanzaro et al., 2003; Kuznetzov et al., 2004; Cavigelli et al., 2005; Chelini et al., 2005).

In mice, corticosterone and testosterone are excreted mainly by feces. Although several reports showed aspects of steroid metabolism in some rodents such as mice during the 1960s and 1970s, new studies have contributed to increase that limited information. Touma et al. (2003) injected mice i.p. with ${ }^{3} \mathrm{H}$-corticosterone; although males excreted significantly more radioactive metabolites via the feces than females (72 vs $56 \%$ ), this study demonstrated once again that most corticosterone metabolite excretion was via the feces in both sexes. Conversely, Kalliokoski et al. (2010) reported that corticosterone metabolite content is about $50 \%$ higher in urine than in feces; therefore, they recommended that future studies should analyze primarily the output in urine, although this matrix is volatile and difficult to collect. Billiti et al. (1998) employed 3 mice and 3 deer mice (3-24 months of age) to perform radiolabeled testosterone infusion (intraperitoneally), and found that the proportion of the injected testosterone excreted in feces was $62 \%$ for Mus spp. and 58\% for Peromyscus spp. Noteworthy, it has been reported that in mice, the rate of excretion vs. time profile showed between two and three elimination phases in urine and feces (and more than 90\% excreted testosterone metabolites were found during first $24 \mathrm{~h}$ ). This information revealed that the first phase 
corresponded to radioactive testosterone that went directly to highly perfused tissues such as liver and kidney, and the second phase corresponded to a slower component in which hormone is sequestered in slowly perfused tissues such as adipose tissues; also, the route of administration, such as the intraperitoneal one, may favor the excretion of testosterone in one phase over another. All these are important considerations not only for future experiments but also for application in field studies.
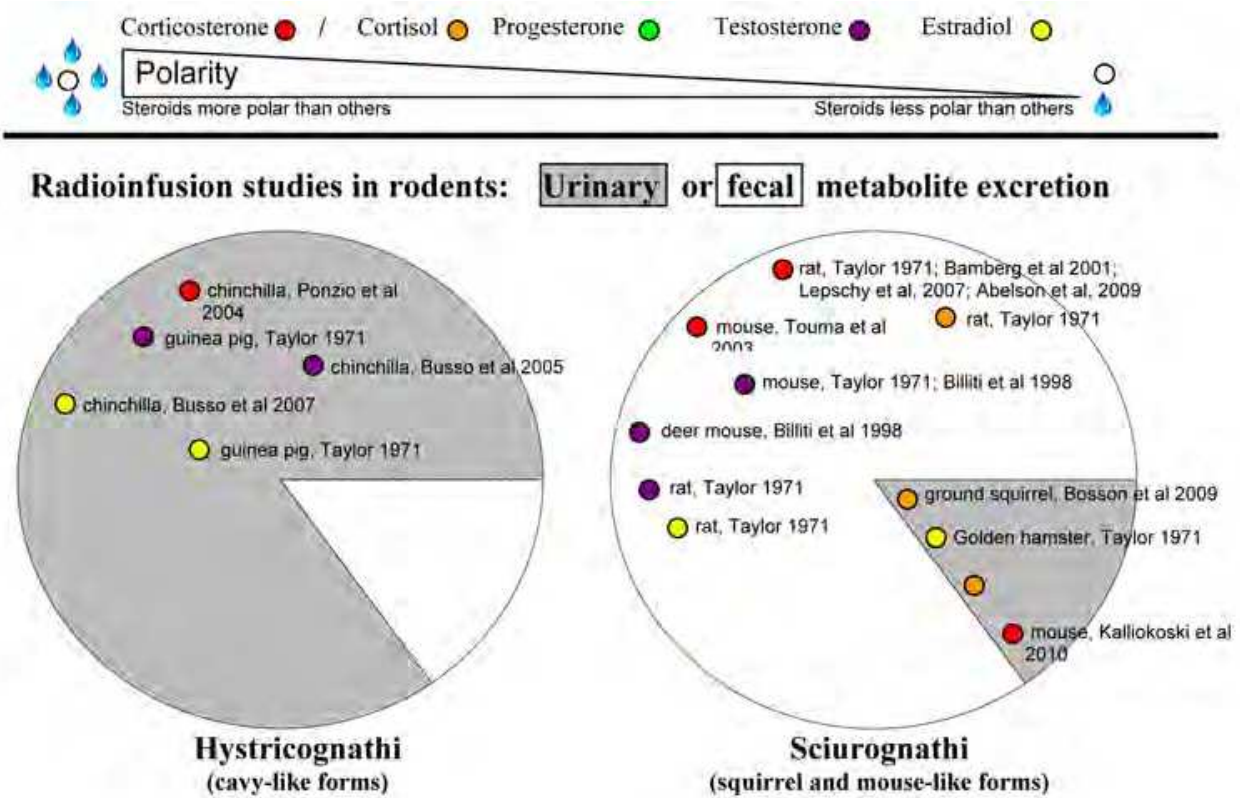

Fig. 2. Compilation of radiometabolism studies in rodent species reported in the literature. Firstly, adrenal and sex steroids are ordered according to solubility in aqueous phase in an "ideal" physical chemistry system in the laboratory. Pie charts are illustrated according to that hypothesis that postulates that in Hystricognathi rodents the urinary route (gray) is preferential, whereas in Sciurognathi, feces (white) is the primary excretory route (details in the text); the size of gray and white portions in both pie charts is only illustrative. Colors of circles are associated with steroids; in addition, circles as well as references were located according to the main route of excretion of each hormone of interest in the studied species, i.e. in Sicurognathi: feces: corticosterone in rat: similar results are revealed by different reports, e.g., Taylor, 1971; Bamberg et al., 2001; Lepschy et al., 2007 and Abelson et al., 2009.

Recently, cortisol radioinfusions were informed for squirrel species (Bosson et al., 2009; Dantzer et al., 2010) as well the application of noninvasive monitoring in Cape ground squirrel (Pettitt et al., 2007). In Columbian ground squirrel, this glucocorticoid is highly metabolized, with virtually none being excreted. The percentages of radioactive cortisol recovered were $31 \%$ and $6.5 \%$ in urine and feces, respectively; it can be argued that these values are low. The authors accepted this problem but, because of the characteristics of excreta collection, results were certain only for feces. Similar results were obtained by Dantzer et al. (2010), who injected radiolabeled cortisol in North American red squirrel; the 
hormone was entirely metabolized and excreted in both urine $(70.3 \pm 0.02 \%)$ and feces $(29.7$ $\pm 0.02 \%$, with a lag time to peak excretion of $10.9 \pm 2.3 \mathrm{~h}$ in feces. With respect to cortisol excretion in mouse-like forms, we found only one reference (for rat, Taylor, 1971); the main route was feces, as well as for corticosterone in other Sciurognathi rodents. Since squirrels belong to the Sciuridade family, which is closer to Lagomorpha than the Muridae family (rat and mouse, etc.), this genetic proximity would explain these results. Accordingly, low fecal excretion of glucocorticoid metabolites (about 8\%) has also been found in European hares (Lepus europaeus; Teskey- Gerstl et al., 2000). In fact, Taylor (1971) informed (another species of Lagomorpha order) that only between $3-5 \%$ of testosterone or $4 \%$ of estradiol are excreted in rabbit feces.

Similarly to the studies analyzed above, different techniques have been applied in rats to monitor the route, time-course and proportions of excreted steroid metabolites. Bamberg et al. (2001) employed male Sprague-Dawley 8 week-old rats which were injected i.p. with ${ }^{3} \mathrm{H}-$ corticosterone $(16 \mu \mathrm{Ci})$ at 09:00. Meanwhile, Lepschy et al. (2007) started an experiment at the same time as the former study; however, each rat (both sexes were employed in this study; 12 week-old individuals) was intravenously injected with different doses of $3 \mathrm{H}$ corticosterone $(62.1 \mu \mathrm{Ci})$. Both studies showed that the main route of corticosterone excretion in the male was feces. It is quite difficult to compare both studies since a different sample collection technique was applied. Firstly, when employing only males, during the first day, urine or feces samples were collected at different time schedule. Lepschy et al. (2007) collected all voided excreta from both sexes during the first day (probably the most recommended). Both radioactive urinary peaks were detected earlier than feces peaks, but there was a great variability in urine: $1-6 \mathrm{~h}$ and $4-10 \mathrm{~h}$, respectively. Technical differences in the study of the same steroid in the same species were further reported by Abelson et al. (2009), who studied male Sprague-Dawley rats after intravenous administration of a low dose $(1 \mu \mathrm{Ci})$ of radioactive corticosterone. The amount of radioactivity detected in feces was highest and displayed a more pronounced peak $12 \mathrm{~h}$ after injection when the substance was administered through a jugular vein catheter than through tail vein injection.

As expected, it is evident that there were great differences in the profiles of radioactive excretion among individuals in rodents, particularly in well studied species such rats and mice, as in others mammals (Brown et al, 1994; Palme et al, 1996), i.e., time course may change with the route and time of administration, even between sexes in some species (see detailed studies on rats: Touma et al., 2003; Eriksson et al., 2004; Abelson et al., 2009). Similarly, in chinchilla, Busso et al. $(2005 a, 2007)$ also indicated that radioactive urinary estradiol peaked between $24-48 \mathrm{~h}$, the radioactive peak being at $34 \mathrm{~h}$ post-infusion. Several technical aspects, rather than biological ones, must be taken into account before deciding to undertake a new investigation; from molecular structure of interested hormone (free marked or conjugated steroid), through animal state and development, up to sample collection regimen, etc. Further studies are necessary to standardize how to obtain endocrinological information from animal "waste" as soon as possible.

A key advantage of measuring hormones in excreta is that this procedure integrates hormone levels over time, instead of measuring a single time point (as in snapshot) represented by hormone levels in blood. We consider that time peak excretion after radioinfusion or steroid hormone increase after gland has been stimulated is not a robust measure because there are too many sources of variation. Several variables, such as dietary preferences, gastrointestinal anatomy, digestive physiology, biochemical capabilities, and commensal microflora, called "nutritional strategy" by Klasing (2005) in birds, may affect 
retention time and consequently time course of excreted steroids among species and/or individuals of the same population. Besides, a different sample collection schedule also seriously affects interpretation of time course or hormonal profiles; collecting naturally all voided urine or feces is advisable, as it has been observed in many reports. Therefore, in attempting to collect all samples, some problems may arise, i.e., in the study of testosterone excretion in chinchilla, an "animal effect" associated with each hormonal profiles was found. This effect evoked a delayed excretion of testosterone metabolites in some males with respect to others; a constipation process was a probable source of variation that has previously been detected in other farmed animals (Palme et al., 1996; Busso et al., 2005a). It is advisable to use each animal as its own control, thereby minimizing the problems of individual differences in basal and peak levels (Touma and Palme, 2005).

Urinary and fecal excretion frequency may be affected by other factors, such as some stressors effects on different individuals. Nowadays, increasing evidence indicates considerable variation between individuals in the magnitude and pattern of their corticosterone responses (called "personalities"). Furthermore, regularity of food intake and resulting defecation frequency has not been investigated sufficiently and needs to be considered as a potential variable for steroid metabolite analyses. In addition, changes in defecation frequency and patterns due to seasonal variation, reproduction, or even stress may alter elimination rate and therefore systematically affect the amount of metabolites excreted per sample (Wielebnowski and Watters, 2007). Further experiments are necessary to enhance our understanding of kinetic parameters; these variables are still significant research topics or unresolved issues that will allow us to elucidate the relationship between physiological events and detection of changes in excreta.

Elimination of steroids via the urine is usually very rapid as maximal concentration is found within a few hours after administration of radioactive tracer and/or peak natural concentrations in the plasma; the first urinary samples collected usually exhibit most of the excreted metabolites. In feces, peak concentrations of radioactivity were observed after a certain lag time (usually after $24 \mathrm{~h}$ or up to 48h) (Monfort, 2003; Palme, 2005; Schwanzenberger, 2007). However, this is not a particularly useful or informative measure as it is highly dependent on the sampling regimen, and fails to account for differences in the general shape of the hormone excretion-time profile (Kalliokoski et al. 2010). Thus, we consider that proportion of total metabolites excreted per activity phase (such as dark/light cycle; endocrine cycles, etc.) would be more informative than the exact time of peak excretion; however, most importantly, hormone monitoring must be performed in repeated long-term studies.

The reviewed information is significantly useful because when monitoring stress and/or reproductive endocrine responses in a long-term study, competitive immunoassays will be used in different matrices (urine, feces, etc) to reveal adrenal and/or gonadal endocrine activities. Thus, depending on the species, the hormone, and the research question, it is relevant to "pick" the appropriate antibody and assay design that allows for detection of most, or at least a considerable amount, of the immunoreactive metabolites involved (Wielebnowski and Watters, 2007). Otherwise, some problems may arise when working with a matrix that exhibits lowest concentration of excreted metabolites. For example, an assay for testosterone fecal metabolites in guinea pig failed to clearly discriminate among intact males, castrated males, and females (Bauer et al., 2008). In addition, it was not possible to detect fecal progestagen changes throughout pregnancy, pre-partum and post-partum stages in chinchilla compared with results obtained from urine samples (Busso et al., 2007). 
This does not mean that we do not recommend working with samples with low steroid concentrations. In fact, there are good examples like the report of Muir et al. (2001), involving urinary samples of female and male mice, since this mouse species excretes reproductive steroids mainly by feces. However, greatest efforts are needed when samples are collected from the less quantitative route of steroid excretion in a given species.

\section{Remarkable issues for a precise assessment of steroid hormone excretion in rodents}

Steroid hormones have demonstrated a major regulatory role in vertebrate physiology (affecting, for example, fetal and postnatal growth and development, and maintaining allostasis, particularly, progesterone or glucocorticoids, as other examples, which are important in female reproduction or are involved in the "fight or flight" response). The physiological changes mediated by adrenal and sex steroids receptors provided early vertebrates with an advantage in competing with the diverse organisms that evolved during the Cambrian explosion (Baker, 1997). Therefore, it is of great importance and interest to study how these hormonal modulators respond to different environmental conditions, such as the studies of chemical disruptors on endocrine activity with implications in normal neuroendocrine responses (Crews et al., 2000; Dickerson and Gore, 2007)

Let's remember that rodents are eutherian mammals (Short, 1985) and that one obvious way of increasing or decreasing an animal's reproductive potential is by altering its gestation length. Three groups stand out with respect to gestation length/maternal weight ratio: hystricomorph rodents as well as primates have relatively long gestations, and whales with relatively short gestations. Hystricomorph rodents, here called cavy-like form, have evidently developed a different reproductive strategy than other rodents. By contrast, Sciurognathi species generally exhibit small body size, short lifespan, short gestation (21 days in mice and rats),numerous litters, and rapid rates of development, as well as short birth intervals (all these species called " $r$ " strategist in ecology). All rodent species together amount to 2000 different taxa; however, information mostly comes from few species of two families (Muridae: Old World mice, rats, gerbils and relatives or Cricetidae: New World rat, mice, voles, hamsters and relatives). These families are genetically closely related and have been well studied: they display differences of degree but not of kind.

Contrarily, Hystricomorph rodents (about 170 species) appear to be more diversified in their patterns of reproduction than any other group of related mammals. The hystricomorph rodents, which are particularly well represented in South America, have colonized harsh environments at either high altitude or high latitudes. Under such conditions, it would be advantageous for a species like the chinchilla to prolong gestation (more than 100 days) so as to allow birth during clement weather. However, this environmental explanation cannot account for the long gestations of those hystricomorphs that live in subtropical forests, or those that live in underground burrows as the plains viscacha (Weir and Rowlands, 1973; Short, 1985; Bronson, 1999). Therefore, this group of mammals (rodents), excluding the human species, is the group of most prosperous modern mammals, occupying very different ecological niches almost worldwide, mostly specialized in different rhythms of reproduction that can be adjusted to different circumstances. This biodiversity offers several phenotypes or biotypes of animals to study general and comparative endocrinological aspects. Finally, how these animals have synchronized to cope with habitats and face environmental challenges up to present is one of our major research concerns. 
Regarding our research work that focused on chinchilla, we considered only steroid excretion in rodents in this chapter. It was not our goal to thoroughly review the details of each species. We found out that few species of rodents were subjected to radiolabeled studies of steroid excretion. According to the latest publications, taxonomic relatedness does little to predict the precise nature of metabolites or their relative routes of excretion (urine versus feces; Palme et al. 2005; Schwanzenberger, 2007). The best way to clarify these questions is to perform radiometabolism experiments and a physiological and biological validation of the immunoassay, such as the work conducted in Columbian ground squirrel (Bosson et al., 2009). However, at present, radioinfusion as an experimental approach to the noninvasive study of adrenal and/or gonadal activity seems "old-fashioned". Accordingly, we did our best to include in the present revision as many reports of application of noninvasive hormone monitoring in rodents species as possible. We also know that it may not be possible to elucidate why different steroids are excreted in urine and feces to different extents; however, a better framework for rodents is now available with respect to differences among species in terms of the same steroid being excreted in urine and feces to different extents. In the assessment of adrenal and gonadal endocrine activities using non-invasive techniques, several extensive considerations should be taken into account (Buchanan and Goldsmith, 2004; Millspaugh and Washburn, 2004; Palme, 2005; Touma and Palme, 2005; Schwarzenberger, 2007; Wilebnowski and Watters, 2007); however, these aspects are beyond the scope of the present revision, but all of them may be affected by the ranking of the excretory routes.

Accordingly, multidisciplinary scientific efforts might be useful to increase our knowledge on comparative endocrinology in rodents, using different species as biotypes or new animal models for the studies. Some concerns about it have already been stated. Smale et al. (2005) pointed out that the study of neuroendocrinology in nontraditional mammals is an essential approach that complements methodologies (such as knock-out mouse) by taking advantage of allelic variation produced by natural selection. Obviously, the technical advantages of non-invasive hormonal monitoring with repeated measures in long-term studies have strongly encouraged biologists (and specialists such as ecologists, ethologists, etc.) as well as other professionals in human and veterinary medicine, zoological exhibition and/or animal production managers.

In summary, the application of noninvasive hormonal monitoring has proven very useful for the generation of normative data (for the species, reproductive cycles, stress responses, etc.) and particularly for the assessment of individual endocrine state. All the aspects shown in Box 2 must be addressed for a precise assessment of steroid hormone excretion.

Finally, one of the main advantages of measuring steroids in blood is the study of the dynamics of hormone secretion; however, great efforts must be made to meet the technical requirements for obtaining a blood sample for an accurate and reliable measurement (route of blood extraction, minimal obtained blood volume, extraction time to avoid stress interference in steroid profiles, etc.). Therefore, hormonal quantification in different biological matrices such urine and feces is an alternative approach. But also, this approach does not exclude technical disadvantages involved in sample collection, such as frequency of elimination of excreta, volume of excreta (which can affect the distribution of hormone metabolites, etc.). Therefore, both types of samples, blood and excreta, are seriously affected by the sampling protocol. Laboratories should continue reviewing (and possibly standardizing) this aspect. In addition, there are extra sources of variation affecting 
sampling protocol such as nutritional strategy, which also seriously alter the precise hormonal determination. Moreover the fact that an individual may be studied without being disturbed, another interesting aspect in the use of non-invasive hormone monitoring is that metabolite concentrations frequently are 2 to 4 times higher than plasma levels (Peter et al., 1996). However, this quantitative advantage is lost when the route of steroid excretion is unknown.

"Keys for a precise assessment of steroid hormone excretion"

- Who? ID of steroids of interest; particularly it is necessary to know species differences and to identify the main glucocorticoid by the adrenal gland in rodents (cortisol or corticosterone).

- How much? Percentage of hormone metabolite excretion into urine or feces; route of excretion may be determined by radiolabeled or unlabeled infusion of each hormone of interest.

- When it happened? Time course of steroid secretion in blood-stream and its clearance into urine and feces. The best approach is to collect all voided urine and excreted feces, because there is still no standardization with respect to sampling protocols. In the future, it seems that proportion of excreted metabolites during activity cycles (day/night; elimination phases) may be a better approach to understanding steroid excretion with respect to individual endocrine state.

- Which matrix? After choosing the biological matrix (urine or feces), identification of steroid metabolite in the matrix of interest is essential to obtain the best results in immunoassay performance. Each matrix has advantages and disadvantages.

- How are results expressed? To follow the endocrine gland activity in the best way possible, it would be useful to express hormone excretion rated by fixed period of time (i.e. hour of sample collection) and to inform total volume or weight/period of time of voided urine and excreted feces, respectively.

- What else? Sex, life stages (juvenile, adult, aging change), environmental characteristics (photoperiod, temperature, feeding strategy, coping strategy) must be taken into account to improve our knowledge.

ID: identification.

Box 2. Recycling information from excretes about animal stress and reproductive endocrine states in rodents.

\section{Acknowledgements}

J. M. Busso jmbusso@conicet.gov.ar and R. D. Ruiz are Established Investigators from CONICET, Argentina and their contributions were supported by CONICET, Agencia Córdoba Ciencia, SECyT-UNC and FONCyT, Argentina.

\section{References}

Abelson, KSP, Fard SS, Nyman J, Goldkuhl R, Hau J. (2009). Distribution of $\left({ }^{3} \mathrm{H}\right)$ corticosterone in urine, feces and blood of male Sprague-Dawley rats after tail vein and jugular vein injection. In Vivo: 23: 381-386. 
Amori G and Gippoliti S, (2003) A higher-taxon approach to rodent conservation priorities for the 21st century. Animal Biodiversity and Conservation, 26: 2: 1-18

Amori, G Gippoliti, S. (2001). Identifying priority ecoregions for rodent conservation at the genus level. Oryx 35, 158-165

Baker, ME. (1997). Steroid receptor phylogeny and vertebrate origins. Mol Cell Endocrinol, 135: 101-107.

Baker, ME. (2003). Evolution of adrenal and sex steroid action in vertebrates: a ligand-based mechanism for complexity. BioEssays, 25: 396-400.

Biddlecombe R.A. and Law B., (1996). Validation of an immunoassay. In Brian Law (ed): Immunoassay a practical guide. Taylor and Francis Ltd, London, pp 171-203.

Blanga-Kanfi S, Miranda H, Penn O, Pupko T, DeBry RW, Huchon D. (2009). Rodent phylogeny revised: analysis of six nuclear genes from all major rodents clades. BMC Evolutionary Biology 9:71, 2148-9-71.

Bosson CO, Palme R, Boonstra R. (2009). Assessment of the stress response in Columbian Ground Squirrels: laboratory and Field validation of an enzyme immunoassay for fecal cortisol metabolites. Physiol Biochem Zool 82: 291-301.

Bogdan D, Monfort SL. (2001). Faecal oestrogen and progesterone profiles in breeding and non-breeding female north American porcupine (Erethizon dorsatum). Mammalia 65, 73-82.

Bradshaw D. (2007). Enviromental endocrinology. Gen Comp Endocrinol, 152: 125-141.

Bronson FH. (1999). Rodentia. In Knobil E, Neill JD (eds): Encyclopedia of reproduction. Academic Press, New York, pp 282-289.

Brookhyser KM, Aulerich RJ, Vomachka AJ. (1977). Adaptation of the orbital sinus bleeding technique to the chinchilla (Chinchilla laniger). Lab. Anim. Sci. 27: 251-254.

Brousset Hernández-Jauregui DM, Galind Maldonado F, Valdez Pérez RA, Romano Pardo M, Schuneman de Aluja A. (2005). Cortisol in saliva, urine, and feces: non-invasive assessment of wild mammals. Vet Mex 36: 325-337.

Brown JL, Wildt DE. (1997). Assessing reproductive status in wild felids by noninvasive faecal steroid monitoring. Int. Zoo Yb. 35, 173-191.

Brown JL, Wasser SK, Wildt DE, Graham LH. (1994). Comparative aspects of steroid hormone metabolism and ovarian activity in felids, measured noninvasively in feces. Biol. Reprod. 51, 776-786.

Brown JL. Steroids hormones-Overview (1999): In Knobil E, Neill JD (eds): Encyclopedia of reproduction. Academic Press, New York, pp 282-289.

Buchanan KL (2000). Stress and the evolution of condition-dependent signals. TREE, 15: 156160.

Buchanan K, Goldsmith A. (2004). Noninvasive endocrine data for behavioural studies: the importance of validation. Anim. Behav. 67: 183-185.

Busso JM, Ponzio MF, Dabbene V, Fiol de Cuneo M, Ruiz RD. (2005a) Assessment of urine and fecal testosterone metabolite excretion in Chinchilla lanigera males. Anim. Reprod. Sci. 86, 339-351.

Busso JM, Ponzio MF, Chiaraviglio M, Fiol de Cuneo M, Ruiz RD. (2005b). Elecroejaculation in the Chinchilla (Chinchilla lanigera): effects of anesthesia on seminal characteristics. Res. Vet. Sci. 78, 93-97. 
Busso JM, Ponzio MF, Fiol de Cuneo M, Ruiz RD. (2005c). Year-round testicular volume and semen quality evaluations in captive Chinchilla lanigera. Anim. Reprod. Sci. 90, 127134.

Busso JM. Estudio de la función reproductora y optimización de biotecnología para mejorar la eficacia reproductiva del género chinchillla. Fac Cs Ex, Fis y Nat-UNC, CórdobaArgentina; Ph D Thesis 2006.

Busso JM, Ponzio MF, Fiol de Cuneo M, Ruiz RD,. (2007) Noninvasive monitoring of ovarian endocrine activity in the chinchilla (Chinchilla lanigera). Gen Comp Endocr; 150: 288-297.

Carrascosa RE, Martini AC, Ponzio MF, Busso JM, Ponce AA, Lacuara JL. (2001). Storage of Chinchilla laniger semen at $4^{\circ} \mathrm{C}$ for 24 or $72 \mathrm{~h}$ with two different cryoprotectants. Cryobiology 42, 301-306.

Cavigelli SA, Monfort SL, Whitney TK, Mechref YS, Novotny M, McClintock MK. (2005). Frequent serial fecal corticoid measures from rats reflect circadian and ovarian corticosterone rhytms. J. Endocrinol. 184, 153-163.

Chelini MOM, Souza NL, Rocha AM, Felippe ECG, Oliveira CA. (2005). Quantification of fecal estradiol and progesterone metabolites in Syrian hamsters (Mesocricetus auratus). Brazilian J of Medical and Biological Research, 38: 1711-1717.

Cepeda R, Adaro L, Peñailillo G. (2006) Morphometric Variations of Chinchilla laniger Prostate and Plasmatic Testosterone Concentration During its Annual Reproductive Cycle. Int J Morphol; 24: 89-97.

Conaway C.H. (1971). Ecological adaptation and mammalian reproduction. Biol. Reprod. 4, 239-247.

Crews D, Willingham E, Skipper JK. (2000). Endocrine disruptors: present issues, future directions. Q Rev Biol 75: 243-260.

Dahlin J, Lam J, Hau J, Astuti P, Siswanto H, Abelson KSP.(2009). Body weight and faecal corticosterone metabolite excretion in male Sprague-Dawley rats following short transportation and transfer from Group-housing to single-housing. Scand. J. Lab. Anim. Sci. 36: 205-213.

Dantzer B, McAdam AG, Palme R, Fletcher QE, Boutin S, Humphries MM, Boonstra R. (2010). Fecal cortisol metabolite levels in free-ranging North American red squirrels: Assay validation and the effects of reproductive condition. Gen Comp Endocrinol 167: 279-286

DeCantanzaro D, Muir C, Beaton EA, Jetha M. (2004). Non-invasive repeated measurement of urinary progesterone, 17 -estradiol, and testosterone in developing, cycling, pregnant, and postpartum female mice. Steroids 69, 687-696.

Dickerson SM, Gore AC. (2007). Estrogenic envrionmental endocrine-disrupting chemical effects on reproductive neuroendocrine function and dysfunction across the life cycle. Rev Endocr Metab Disord 8: 143-159.

Eriksson E, Royo F, Lyberg K, Carlsson H-E, Hau J. (2004). Effect of metabolic cage housing on immunoglobulin A and corticosterone excretion in faeces and urine of young male rats. Exp Physiol 89, pp 427-433

Fajer AB, Vogt M. (1963). Adrenocortical secretion in the Guinea-pig. J Physiol, 169: 373-385.

Frynta D, Nováková M, Kutalová H, Palme R, Sedlácek. (2009). Apparatus for collection of fecal samples from undisturbed Spiny mice (Acomys cahirinus)living in a complex social group. J Am Assoc Lab Anim Sci. 48: 196-201. 
Gippoliti S, Amori G. (1998). Rodent conservation, zoos, and the importance of the "common species". Zoo Biol. 17, 263-265.

Good T, Khan MZ, Lynch WL. (2003). Biochemical and physiology validation of a corticosteroid radioimmunoassay for plasma and fecal samples in oldfield mice (Peromyscus polionotus). Physiol and Behav 80: 405- 411.

Goymann, W. (2005). Noninvasive monitoring of hormones in bird droppings. Physiological validation, sampling, extraction, sex differences, and the influence of diet on hormone metabolite levels. Ann NY Acad Sci 1046; 35-53.

Gromadzka-Osrttowska J, Zalewka B, Szylarska-Gozdz E. (1985). Peripheral plasma progesterone concentration and hematological indices during normal pregnancy of Chinchillas (Chinchilla laniger). Comp. Biochem. Physiol. 82 A, 661-665.

Gromadzka-Ostrowska, Zalewska B. (1984). Progesterone concentration and their seasonal changes during the estrus cycle of chinchilla. Acta. Theriogenology. 20: 251-258.

Harper JM, Austad SN. (2000). Fecal glucocorticoids: a noninvasive method of measuring adrenal activity in wild and captive rodents. Physiol. Biochem. Zool. 73, 12-22.

Hayssen V, Harper JM, DeFina R. (2002). Fecal corticosteroids in agouti and non-agouti deer mice (Peromyscus maniculatus). Comp. Biochem. Physiol., A, 132: 439- 446.

Hayward LS, Booth R, Wasser S. (2010). Eliminating the artificial effect of sample mass on avian fecal hormone metabolite concentration. Gen Comp Endocrinol, 169: 117-122

Homyack JA. (2010). Evaluating habitat quality of vertebrates using conservation physiology tools. Wildlife Res, 37: 332-342.

Huchon D, Madsen O, Sibbald MJJB, Ament K, Stanhope MJ, Catzeflis F, de Jong WW, Douzery EJP ( 2002). Rodent phylogeny and timescale for the evolution of glires: evidence from an extensive taxon sampling using three nuclear genes. Mol. Biol. Evol. 19: 1053-1065.

Kalliokoski O, Hua J, Jacobsen KR, Schumacher-Petersen C, Abelson KSP. (2010). Distribution and time course of corticosterone excretion in faces and urine of female mice with varying systemic concentrations. Gen Comp Endocrinol, 168: 450454 .

Kay EH, Hoekstra HE. (2008). Rodents. Current Biol, 18 R406-R410.

Klasing, KC (2005). Potential impact of nutritional strategy on noninvasive measurements of hormones in birds. Ann. N Y Acad. Sci. 1046: 5-16.

Kuznetsov VA, Tchabovsky AVT, Kolosova IE, Moshkin MP. (2004). Effect of habitat type and population density on the stress levels of Midday Gerbils (Meriones meridianus Pall) in free-living populations. Biol Bull Russ Acad Sci, 31: 628-632.

Arora KL. (1979). Blood sampling and intravenous injections in Japanese quail (Coturnix coturnix japonica). Lab Anim Sci. 29:114-118.

Lèche A, Busso JM, Navarro JL, Hansen C, Marín RH, Martella MB. (2011). Non-invasive monitoring of adrenocortical activity in Greater Rhea (Rhea americana) by measuring fecal glucocorticoid metabolites. Journal of Ornithology, in press.

Lèche A, Busso JM, Hansen C, Navarro JL, Marín RH, Martella MB (2009) Physiological stress in captive Greater rheas (Rhea americana): Highly sensitive plasma corticosterone response to an ACTH challenge. Gen Comp Endocrinol 162: 188-192

Malinowska KW, Nathanielsz PW. (1974). Plasma aldosterone, cortisol and corticosterone in the new-born guinea-pig. J. Physiol. 236: 83-93. 
McEwen BS, Wingfield JC (2003). The concept of allostasis in biology and biomedicine. Horm and Behavior, 43: 2-15.

Mess A, Mohr B, Martin T. (2001). Evolutionary transformations of hystricognath rodentia and the climantic change in the Eocene to late Oligocene time interval. Zoossystmatics and Evol, 77: 193-206

Millspaugh J.J., Washburn B.E. (2004). Use of fecal glucocorticoid metabolite measures in conservation biology research: considerations for application and interpration. Gen. Comp. Endocrinol. 138, 189-199.

Moberg GP. (2000). Biological response to stress: implications for animal welfare. Chapter 1, in: Moberg GP, Mench JA (eds). The biology of animal stress. Basic principles and implications for animal welfare. CAB International, pp 1-22.

Monfort SL. (2003). Non-invasive endocrine measures of reproduction and stress in wild population. In Holt WV, Pickard AR, Rodger JC, Wild DE. (eds). Reproductive Science and integrated Conservation, Cambridge, London, pp 146-165.

Moreira N, Brown JL, Moraes W, Swanson WF, Monteiro-Filho EL. (2007). Effect of housing and environmental enrichment on adrenocortical activity, behavior and reproductive cyclicity in the female tigrina (Leopardus tigrinus) and margay (Leopardus wiedii). Zoo Biol, 26:441-60

Mormède $\mathrm{P}$, Andanson S, Aupérin B, Beerda B, Guémené D, Malmkvist J, Manteca X, Manteuffel G, Prunet P, Van Reenen CG, Richard S, Veissier I. (2007). Exploration of the hypothalamic-pituitary-adrenal function as a tool to evaluate animal welfare. Physiol and Behav, 92: 317-339.

Möstl E., Palme R. (2002). Hormones as indicators of stress. Domest Anim Endocrinol 23: 67-74

Muir C, Spironello-Vella E, Pisani N, deCatanzaro D. (2001). Enzyme immunoassay of 17ßEstradiol, estrone conjugates, and $\mathrm{T}$ in urinary and fecal samples from males and female mice. Horm. Metab. Res. 33,653-658.

Norris DO. (2007). Synthesis, Metabolism, and Actions of Bioregulators. In Vertebrate endocrinology, Fourth Edition. Elsevier Academic Press, pp 46-105.

Nováková M, Palme R, Kutalová H, Jansky L, Frynta D. (2008). The effects of sex, age and commensal way of life on levels of fecal glucocorticoid metabolites in spiny mice (Acomys cahirinus). Physiology and Behavior, 95: 187-193.

Opazo JC, Palma RE, Melo F, Lessa EP. (2005). Adaptative evolution of the insulin gene in Caviomorph Rodents. Mol. Biol. Evol. 22:1290-1298.

Pettitt BA, Wheaton CJ, Waterman JM. (2007). Effects of storage treatment on fecal steroid hormone concentrations of a rodent, the Cape ground squirrel (Xerus inauris). Gen Comp Endocrinol 150: 1-11.

Palme R, Fischer P, Schildorfer H, Ismail MN. (1996). Excretion of infused 14C-steroid hormones via faeces and urine in domestic livestock. Anim Reprod Sci, 43: 43-63.

Palme R., S. Rettenbacher, C. Touma, S.M. El-Bahr, and Möstl E. 2005. Stress hormones in mammals and birds: comparative aspects regarding metabolism, excretion, and noninvasive measurement in fecal samples. Ann N Y Acad Sci 1040:162-171.

Palme, R. (2005). Measuring fecal steroids: guidelines for practical application. Ann. N.Y. Acad. Sci. 1046: 75-80.

Peter, A. T., N. Kapustin, and J. K. Critser. (1996). Analysis of sex steroid metabolites excreted in the feces and urine of nondomesticated animals. Compend Contin Educ Pract Vet 18:781-789. 
Ponce AA, Carrascosa RE, Aires VA, Fiol de Cuneo M, Ruiz RD, Ponzio MF Lacuara JL. (1998a) Activity of Chinchilla laniger spermatozoa collected by electroejaculation and cryopreserved. Theriogenology 50, 1239-1249.

Ponce AA, Aires VA, Carrascosa RE, Fiol de Cuneo M, Ruiz RD, Lacuara JL. (1998b). Functional activity of epididymal Chinchilla laniger spermatozoa cryopreserved in different extenders. Res. Vet. Sci. 64, 239-243.

Ponzio MF, Monfort SL, Busso JM, Dabbene VG, Ruiz RD, Fiol de Cuneo M. (2004). A noninvasive method for assessing adrenal activity in the chinchilla (Chinchilla lanigera). J. Exp. Zool. 3, 218-227.

Ponzio MF. “Detección de situaciones potencialmente estresantes y su repercusión sobre la fisiología reproductiva en un modelo animal (Chinchilla laniger)". Fac Cs Ex, Fis y Nat-UNC, Córdoba-Argentina; Ph D Thesis 2006.

Ponzio MF; Busso JM, Ruiz RD, Fiol de Cuneo, M. (2007) Time-related changes in functional activity and capacitation of chinchilla (Chinchilla lanigera) spermatozoa during in vitro incubation. Anim Reprod Sci; 102: 343-349.

Ponzio MF; Busso JM, Ruiz RD, Fiol de Cuneo, MF, Ponce, AA (2008). Functional activity of frozen thawed Chinchilla lanigera spermatozoa cryopreserved with glycerol or ethyleneglycol. Reprod Dom Anim; 43: 228-233.

Pukazhenthi BS, Wild DE. (2004). Which reproductive technologies are most relevant to studying, managing and conserving wildlife? Reprod Fert and Develp 16: 33-46.

Romero LM. (2004). Physiological stress in ecology: lessons from biomedial research. Trends in Ecol Evol, 19: 249-255.

Romero LM, Reed JM. (2005). Collecting baseline corticosterone samples in the field: is under 3 min good enough? Comp Biochem Physiol, Part A 140: 73- 79.

Sapolsky RM, Romero LM, Munck AU. (2000). How do glucocorticoids influence stress responses? Integrating permissive, suppressive, stimulatory, and preparative actions. Endocr. Rev. 21:55-89.

Schneider JE. (2004). Energy balance and reproduction. Physiol and Behav, 81: 289-317.

Schwarzenberger F, Möstl E, Palme R, Bamberg E. (1996). Faecal steroid analysis for oninvasive monitoring of reproductive status in farm, wild and zoo animals. 1, Anim Reprod Sci 42: 515-526.

Schwarzenberger F. (2007) The many uses of non-invasive faecal steroid monitoring in zoo and wildlife species. Inter Zoo Yearbook; 41: 52 - 74

Sheriff MJ, Dantzer B, Delehanty B, Palme R, Boonstra R. (2011). Measuring stress in wildlife: techniques for quantifying glucocorticoids. Oecologia Feb 23. [Epub ahead of print]

Short, RV. Species differences in reproductive mechanisms. (1985). In Austin CR, and Short RV (eds): chapter 2, Reproduction in mammals. Cambridge University Press, pp 62-101.

Siswanto H, Hau J, Carlsson H-E, Goldkuhl R, Abelson KSP. (2008). Corticosterone concentration in blood and excretion in faces after ACTH administration in male Sprague-Dawley rats. In Vivo (International Journal of Experimental and Clinical Pathophysiology and Drug Research), 22:435-440.

Soto Gamboa M, Gonzalez S. (2009). Validation of a radioimmunoassay for measuring fecal cortisol metabolites in the hystricomorph rodent, Octodon degus. J Exp Zool, 311A:496-503. 
Smale L, Heideman PD, French JA. (2005). Behavioral neuroendocrinology in nontraditional species of mammals: things the 'knockout' mouse CAN'T tell us. Horm Behav, 48: 474-483.

Swanson WF, Brown JL. (2004). Internation training programs in reproductive sciences for conservation of Latin American felids. Anim Reprod Sci, 82-83: 21-34.

Tam W.H. (1971). The production of hormonal steroids by ovarian tissues of the chinchilla (Chinchilla lanigera). J. Endocr. 50, 267-279.

Tam WH (1972). Steroid metabolic pathways in the ovary of the chinchilla (Chinchilla laniger). J Endocr; 52: 37-50.

Tappa B, Amao H, Takahashi KW (1989). A simple method for intravenous injection and blood collection in the chinchilla (Chinchilla laniger). Lab Anim 23: 73-75.

Taylor W., (1971). The excretion of steroid hormone metabolites in bile and feces. Vitam. Horm. N.Y. 29, 201-285.

Thanos PK, Cavigelli SA, Michaelides M, Olvet DM, Patel U, Diep MN, Volkow. (2009). A non-invasive method for detecting the metabolite stress response in rodents: characterization and disruption of the circadian corticosterone rhythm. Physiol Res 58: 219-228.

Terlouw EMC. Schouten WGP, Ladewig J. Physiology (1997). In: Appleby MC, Hughes Bo (eds), chapter 10 Animal Welfare. CABI International, pp 143-158.

Teskey-Gerstl A, Bamberg E, Steineck T, Palme R. (2000). Excretion of corticosteroids in urine and faeces of hares (Lepus europaeus). J. Comp. Physiol. B. 170, 163-168.

Touma C., Sachser N., Mostl E., and Palme R., (2003). Effects of sex and time of day on metabolism and excretion of corticosterone in urine and feces of mice. Gen. Comp. Endocrinol. 130, 267-278.

Touma C, Palme R. (2005). Measuring fecal glucocorticoid metabolites in mammals and birds: the importance of validation. Ann N Y Acad Sci 1046:54-74.

Touma C, Palme R, Sachser N. (2005). Analyzing corticosterone metabolites in fecal samples of mice: a noninvasive technique to monitor stress hormone. Horm and Behav, 45: $10-22$.

Wasser SK, Kathleen EH, Brown JL, Cooper K, Crockett CM, Bechert U, Millspaugh JJ, Larson S, Monfort SL. (2000). A generalized fecal glucocorticoid assay for use in a diverse array of nondomestic mammalian and avian species. Gen. Comp. Endocr. $120,260-275$.

Weir BJ, Rowland IW. (1973). Reproductive strategies of mammals. Annu Rev Ecol Syst 4: 139-163.

Wielebnowski N. (2003). Stress and distress: evaluating their impact for the well-being of zoo animals. J. Am. Vet. Med. Assoc. 223, 973-977.

Wielebnowski NC, Fletchall N, Carlstead K, Busso JM, Brown JL. (2002). Noninvasive assessment of adrenal activity associated with husbandry and behavioral factors in the North American clouded leopard population. Zoo Biol. 21, 77-98.

Wielebnowski N, Watters J. (2007). Applying fecal endocrine monitoring to conservation and behavior studies of wild mammals: important considerations and preliminary tests. Israel J Ecology and Evolution, 53: 439-460.

Young JZ. (1985). Roedores y lagomorfos. En: La vida de los vertebrados. Ediciones Omega, Barcelona, pp 533-542. 


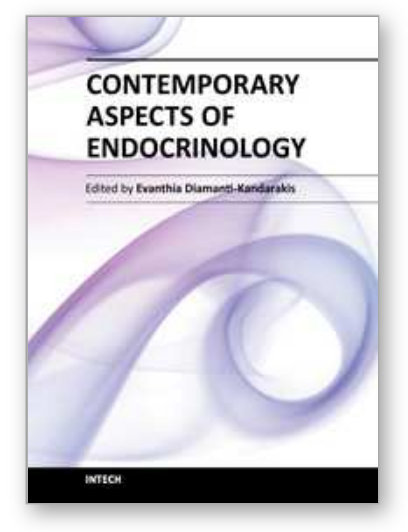

\author{
Contemporary Aspects of Endocrinology \\ Edited by Dr. Evanthia Diamanti-Kandarakis
}

ISBN 978-953-307-357-6

Hard cover, 454 pages

Publisher InTech

Published online 30, November, 2011

Published in print edition November, 2011

This book aims to provide readers with a general as well as an advanced overview of the key trends in endocrine disorders. While covering a variety of topics ranging from thyroid carcinogenesis and pituitary adenomas to adrenal tumors and metabolic bone disease, this book also focuses on more specific issues not yet fully elucidated (e.g. the molecular pathways involved in thyrotropin beta gene regulation or monogenic phosphate balance disorders). Readers of different fields and background will have the opportunity to update their knowledge and more importantly to clarify areas of uncertainty and controversies in several topics of endocrine disorders.

\title{
How to reference
}

In order to correctly reference this scholarly work, feel free to copy and paste the following:

Juan Manuel Busso and Rubén Daniel Ruiz (2011). Excretion of Steroid Hormones in Rodents: An Overview on Species Differences for New Biomedical Animal Research Models, Contemporary Aspects of Endocrinology, Dr. Evanthia Diamanti-Kandarakis (Ed.), ISBN: 978-953-307-357-6, InTech, Available from: http://www.intechopen.com/books/contemporary-aspects-of-endocrinology/excretion-of-steroid-hormones-inrodents-an-overview-on-species-differences-for-new-biomedical-anima

\section{INTECH}

open science | open minds

\section{InTech Europe}

University Campus STeP Ri

Slavka Krautzeka 83/A

51000 Rijeka, Croatia

Phone: +385 (51) 770447

Fax: +385 (51) 686166

www.intechopen.com

\section{InTech China}

Unit 405, Office Block, Hotel Equatorial Shanghai

No.65, Yan An Road (West), Shanghai, 200040, China

中国上海市延安西路65号上海国际贵都大饭店办公楼405单元

Phone: +86-21-62489820

Fax: $+86-21-62489821$ 
(C) 2011 The Author(s). Licensee IntechOpen. This is an open access article distributed under the terms of the Creative Commons Attribution 3.0 License, which permits unrestricted use, distribution, and reproduction in any medium, provided the original work is properly cited. 